\title{
CONCEPÇÕES DE USUÁRIOS DE UM CAPS SOBRE O TRATAMENTO E
} INCLUSÃO

\author{
CONCEPCIONES DE USUARIOS DE UN CAPS SOBRE EL TRATAMIENTO Y \\ LA INCLUSIÓN \\ CONCEPTIONS OF USERS OF A CENTER FOR PSYCHO-SOCIAL ATTENTION \\ (CAPS) ABOUT TREATMENT AND INCLUSION
}

http://dx.doi.org/10.1590/1807-0310/2018v30187474

\author{
Giselli Lucy Souza Vieira ${ }^{1}$, Lívia Sales Cirilo ${ }^{2}$, Patrícia Fonseca de Sousa ${ }^{1}$ e Silvana Carneiro Maciel ${ }^{1}$ \\ ${ }^{1}$ Universidade Federal da Paraíba, João Pessoa/PB, Brasil \\ ${ }^{2}$ Universidade Estadual da Paraíba, João Pessoa/PB, Brasil
}

\begin{abstract}
RESUMO
Este trabalho teve como objetivo analisar as concepções sobre o tratamento, encontradas nos discursos de usuários de um serviço substitutivo de saúde, bem como os sentidos por eles atribuídos à sua relação com a comunidade. Foi adotado o referencial teórico da Psicologia Social, particularmente da Teoria da Produção de Sentidos, que estuda a análise das práticas discursivas por um viés construcionista. Aplicou-se uma entrevista semiestruturada a homens e mulheres egressos de hospitais psiquiátricos e acompanhados pelo CAPS II, no município de XX, em uma amostra de dez participantes. Os depoimentos dos participantes mostraram a ênfase no conceito de doença, a atribuição de fatores externos como principais causas da doença mental e a percepção do hospital como um lugar de isolamento e maus-tratos. Mesmo com as novas formas de tratamento proporcionadas pela Reforma Psiquiátrica, os sentimentos de exclusão e rejeição foram destacados pelos usuários.
\end{abstract}

Palavras-chave: saúde mental; reforma psiquiátrica; análise de discurso.

\section{RESUMEN}

El objetivo fue analizar las concepciones sobre el tratamiento encontradas en los discursos de usuarios de un servicio sustitutivo de salud, así como los sentidos por ellos atribuidos a su relación con la comunidad. Se adoptó el referencial teórico de la Psicología Social, particularmente de la Teoría de la Producción de Sentidos, que estudia el análisis de las prácticas discursivas por un sesgo construccionista. Se aplicó entrevista semiestructurada a hombres y mujeres egresados de hospitales psiquiátricos y acompañados por el CAPS II en el municipio de XX, en una muestra de diez participantes. Los testimonios de los participantes señalaron el concepto de enfermedad y la atribución de factores externos como principales causas de la enfermedad mental y la percepción del hospital como lugar de aislamiento y maltrato. Aunque existen nuevas formas de tratamiento proporcionadas por la Reforma Psiquiátrica, los sentimientos de exclusión y rechazo fueron destacados por los usuarios.

Palabras clave: salud mental; reforma psiquiátrica; análisis de discurso.

\begin{abstract}
This study aimed to analyze the conceptions about the treatment, found in the speeches of users from a substitutive health service, and the meanings they attributed to their relationship with the community. The theoretical approach of Social Psychology was adopted, particularly the Theory of Meaning Production, which studies the analysis of discursive practices by a constructionist approach. A semi-structured interview was applied to a sample of ten participants, these being men and women who come from psychiatric hospitals and accompanied by CAPS II, in the city of XX. The testimonials of the participants showed an emphasis in the concept of disease, the attribution of external factors as the main causes of mental illness and the perception of the hospital as a place of isolation and mistreatment. Even with the new methods of treatment provided by the Psychiatric Reform, users highlighted feelings of exclusion and rejection.
\end{abstract}

Keywords: mental health; psychiatric reform; discourse analysis. 


\section{Introdução}

A produção do cuidado em saúde mental seguiu por muitos séculos o modelo manicomial: hospitalocêntrico, segregador, higienista e tutelar, porém, na virada deste século, com a ascensão do movimento reformista de redemocratização do país e, por conseguinte, das reformas sanitária e psiquiátrica, tem-se a proposição de uma mudança paradigmática no horizonte da assistência à saúde mental (Rodrigues $\&$ Yasui, 2016).

No Brasil, as transformações no modelo de assistência à saúde mental foram contemporâneas às discussões suscitadas pela Reforma Sanitária, nos anos 70, que propunha a transformação da saúde pública nacional. As reflexões sobre a saúde no país provocaram críticas à institucionalização e às terapêuticas aplicadas às pessoas com transtornos mentais, possibilitando a emergência de novas práticas e propondo novas relações entre a sociedade e o transtorno mental (Amarante \& Nunes, 2018).

No final do século XX, os avanços biológicos, humanos e sociais, além do advento dos psicofármacos, proporcionaram um redirecionamento do olhar da sociedade com relação à saúde mental. A socialização da pessoa com transtorno mental começou a ser percebida como um método auxiliar ao tratamento, com uma assistência mais humanizada e integrada, com inspiração no movimento italiano proposto por Franco Basaglia, o qual serviu de modelo para a Reforma Psiquiátrica brasileira (Feitosa et al., 2010).

Apesar de possuir contornos próprios, a Reforma Psiquiátrica no Brasil seguiu o modelo italiano das comunidades terapêuticas, ela surgiu como Projeto de Lei no 3.657 na Câmara Federal, no ano de 1989, pelas mãos do então deputado Paulo Delgado, e tramitou durante doze anos, até a sanção da Lei da Reforma Psiquiátrica (Lei no 10.216/2001), em 06 de Abril de 2001.

A Reforma Psiquiátrica propôs uma estratégia de cuidado em saúde mental de base comunitária, que não é apenas uma rede de serviços que busca substituir o manicômio, mas representa outro paradigma de cuidado: o paradigma psicossocial, que se contrapõe ao paradigma biomédico. Essa mudança paradigmática vai do modelo médico-biológico e das instituições totais para a organização de serviços humanos, inseridos na comunidade e que consideram os doentes mentais como sujeitos e não como objetos. Isso implica em uma mudança de concepção sobre o que seja tratar/cuidar, sendo o paradigma biomédico centrado no controle de sintomas e comportamentos, na fragmentação do usuário e na distância entre este e o profissional, já o paradigma psicossocial é voltado para a compreensão do sofrimento da pessoa real, do seu contexto de vida e de suas necessidades concretas, incluindo aquelas psicológicas e subjetivas, ou seja, a Reforma Psiquiátrica extrapola as modificações técnico-assistenciais e envolve a mudança em todo o status quo de segregação e exclusão social vivenciado pelos portadores de transtornos mentais (Shimoguiri \& Costa-Rosa, 2017).

Nesse sentido, as mudanças propostas pela reforma extrapolam a dimensão da assistência e perpassam também dimensões políticas, sociais e culturais, as quais compõem um amplo projeto de transformação social. Dessa forma, a mudança na forma de produzir cuidado vem se consolidando como um processo social complexo, preconizado pelo ideal de desinstitucionalização e caracterizado por: assistência que visa a autonomia e corresponsabilização do sujeito em seu tratamento. Além disso, o novo cuidar atribui ao usuário poder de contratualidade em seu processo de reabilitação psicossocial; projetos e itinerários terapêuticos vinculados ao território e ao princípio de fortalecimento da convivência familiar e comunitária do usuário (Firmo \& Jorge, 2015).

Como afirma Silva (2014), na nova realidade social proposta pela Reforma Psiquiátrica, não apenas a saúde pública e a estruturação dos serviços são modificadas, alterações na relação entre a pessoa com transtorno mental e a sociedade também são suscitadas, haja vista que o usuário que antes era mantido isolado, ou até mesmo abandonado em um hospital psiquiátrico, agora passa a circular livre pelas ruas e, como preconiza a Reforma Psiquiátrica, faz uso de dispositivos comunitários, como praças, centros de convivência, associações e outros, que antes eram comuns apenas aos ditos normais.

Uma mudança dessa ordem implica muitos desafios e ações intersetoriais. Em função disso, faz-se importante estudar como os usuários dos serviços substitutivos compreendem as mudanças advindas com a Reforma Psiquiátrica, dando voz a esse grupo social e entendendo a reforma a partir da ótica de quem a vivencia cotidianamente. Diante dessa nova configuração do campo da saúde mental, é imprescindível que os usuários dos novos dispositivos de saúde participem das discussões travadas sobre a Reforma Psiquiátrica e apontem elementos relevantes ou práticas reprodutoras dos antigos asilos psiquiátricos.

Para tanto, o presente estudo tem como objetivos: analisar as concepções sobre o tratamento, encontradas nos discursos de usuários de um CAPS, bem como os 
sentidos produzidos por estes usuários no que se refere à inclusão social.

A averiguação de tais aspectos poderá trazer um feedback acerca da configuração da assistência no âmbito dos CAPS (Centro de Atenção Psicossocial), o que poderá ser importante para a implementação de mudanças ou fortalecimento de práticas existentes. Conforme Mielke, Kantorski, Jardim, Olschowsky e Machado (2009), estudos que se propõem a realizar alguma avaliação no cenário da reforma são relevantes por servirem como um instrumento potencial para a efetivação das práticas psicossociais. Soma-se a isso o fato dessa pesquisa suscitar uma reflexão acerca do processo de inclusão da pessoa com transtorno mental na sociedade, algo fundamental para a real efetivação da Reforma Psiquiátrica.

\section{Método}

\section{Local da pesquisa}

Este estudo foi realizado com os usuários do CAPS II, da cidade de Campina Grande. A escolha pelo CAPS II se deu por ser este o primeiro serviço substitutivo implantado no município. $\mathrm{O}$ serviço registra, atualmente, 463 usuários acolhidos.

\section{Tipo de pesquisa}

Trata-se de um estudo qualitativo, pois possibilita uma relação mais estreita com a subjetividade do indivíduo, não possuindo a pretensão de generalização dos dados, mas sim de dar voz a uma parcela da população que foi negligenciada por muitos anos; aprofundando a dimensão psicossociológica contida nos discursos dos usuários (Minayo, 1995).

\section{Participantes}

Participaram desse estudo 10 (dez) sujeitos, sendo 03 homens e 07 mulheres, com idades que variavam entre 29 e 60 anos de idade. Quanto ao grau de escolaridade, foram entrevistados 02 usuários não alfabetizados, 05 que possuíam o Ensino Fundamental, 01 que possuía o Ensino Médio completo e 02 que possuíam o Ensino Superior. Na escolha dos participantes, considerou-se os seguintes critérios de inclusão: que os participantes já tivessem sido, em algum momento, internos em hospitais psiquiátricos; que, por ocasião da pesquisa, não se encontrassem em crise e não demonstrassem maiores comprometimentos cognitivos; além disso, deveriam possuir disponibilidade e interesse em participar da pesquisa. Para tanto, foi solicitado auxílio à coordenação e à equipe técnica do
CAPS, para que os usuários fossem identificados. Todos os entrevistados receberam nomes fictícios durante a pesquisa, respeitando-se, assim, o seu anonimato.

\section{Instrumentos}

Foram realizadas entrevistas semiestruturadas, elaboradas a partir de um roteiro com os principais temas a serem abordados. As perguntas versavam sobre o motivo pelo qual os usuários estarem sendo atendidos no CAPS; sobre o tratamento oferecido nas instituições hospitalares; e sobre a percepção dos usuários no tocante à sua condição de usuário de serviço de saúde mental e à sua relação com a comunidade. Além disso, foi aplicado um questionário sociodemográfico (nome, idade, estado civil e tempo de uso dos serviços psiquiátricos).

\section{Procedimento}

Esse estudo foi aprovado pelo Comitê de Ética da Universidade Estadual da Paraíba, sob protocolo de número 0060.0.133.000-11. A coleta dos dados, realizada por meio de entrevista individual e gravada, foi realizada no próprio CAPS, em espaço reservado. Cabe acrescentar que os participantes foram previamente informados sobre o propósito da pesquisa, o sigilo das informações fornecidas e a possibilidade de cancelar sua participação no estudo se assim desejassem. Os entrevistadores foram estudantes universitários previamente treinados para tal procedimento. Os entrevistados iniciavam a participação no estudo mediante a assinatura do Termo de Consentimento Livre e Esclarecido. Os participantes levaram, em média, uma hora para concluir a participação na pesquisa.

\section{Análise dos dados}

As entrevistas foram gravadas e transcritas na íntegra. Após a transcrição das entrevistas, foi realizada a codificação do material transcrito, a fim de, como diz Potter e Wetherrel (1987, p. 09), "espremer o corpo do discurso conseguindo partes manuseáveis". A codificação possibilitou um estudo mais aprofundado e a análise, propriamente dita, do material.

A orientação teórico-metodológica utilizada para análise das entrevistas foi a da Psicologia Social Discursiva, que concebe o discurso como uma produção da interação social. Neste sentido, "o discurso não é apenas o ato de falar, não é a exteriorização de um pensamento, a descrição de uma realidade. Falar é fazer algo, é criar aquilo de que se fala, quando se fala" (Iñiguez, 2004, p. 95). 
Durante a análise, o foco da atenção esteve voltado para a organização, função e modo como os discursos foram construídos. De acordo com alguns autores, este cuidado é necessário porque os discursos não se restringem a uma reprodução da prática cotidiana, tendo preferentemente um objetivo (Gill, 2002; Potter \& Wetherrel, 1987). Portanto, o trabalho procurou identificar estes objetivos, além dos sentidos que foram produzidos. Nesta perspectiva, pode-se dizer que a pesquisa se colocou como um processo de comunicação, como uma via de construção do conhecimento. Como assinalam Lima e Surjus (2007, p. 73), "a narração parece poder provocar, por meio de uma "re-volta", uma revisitação ao experimentado com um novo olhar transformador, insinuando alguns efeitos de avaliação, construtores de outras e tantas narrativas que certamente virão".

\section{Resultados e discussão}

\section{Sentidos produzidos sobre saúde mental e causa do transtorno mental}

Com o intuito de analisar as concepções sobre o tratamento, algumas perguntas foram feitas aos entrevistados, tais como: Por que você está aqui? Você acha que ficou assim por quê? As perguntas foram feitas sem a utilização de nenhuma nomenclatura, pois objetivavam verificar como os usuários percebiam a assistência, como nomeavam o seu transtorno psíquico, bem como a sua causa. Cabe acrescentar que quando questionados sobre o tempo decorrido desde que receberam o primeiro diagnóstico psiquiátrico, os entrevistados relataram um período que variava entre 06 e 45 anos.

Sendo assim, alguns entrevistados se autonomearam a partir do seu diagnóstico, o que caracteriza a rotulação, marcante no modelo asilar e que tem como característica a redução do sujeito a sua enfermidade, enxergando-o como uma doença e não como um indivíduo que apresenta especificidades e infinitas possibilidades (Sousa, Maciel, Medeiros, \& Vieira, 2016). Tal fato pode ser observado no depoimento abaixo:

\section{Participante:}

É... Eu tenho transtorno bipolar. É uma oscilação de sentimentos, né? Uma hora a gente tá bem... bem assim... bem valorizado, né? De repente, bate uma tristeza, essas coisas assim, oscila muito o sentimento, é por isso que tem que tá [iㅗ] alguém sempre consolando. Entrevistador: Tem que está alguém consolando, é? Participante: É! O que a gente quer mesmo é ser saudável, né? Eu não gostaria de ter essa doença não, mas infelizmente eu tenho e agora que eu já sei é tratar, né? Entrevistador: Você gostaria de ser saudável? Participante: Eu gostaria $\underline{\text { muito }}$ [grifo nosso], era totalmente... seria totalmente diferente se eu não tivesse essa doença, né? Porque também tem essa questão de... de... quando a pessoa é bipolar... quando a gente é bipolar, que fica... tem uma sede muito grande de sexo. Na crise, né? Fica incontrolável, a pessoa sai como se fosse à procura disso... [pausa]. Também aí a questão disso, não é como se eu, às vezes era como se eu não mandasse em mim mesma. (Silene, 29 anos, há 6 anos é usuária de serviço de saúde mental)

Silene chama atenção para a oscilação dos seus sentimentos, que vão de uma supervalorização até uma tristeza profunda, parecendo valorizar a instabilidade causada pelo transtorno bipolar. Este fato é reforçado ao longo do seu discurso, quando mais adiante ela relata "uma sede muito grande de sexo", ficando "incontrolável", ao ponto de não ter domínio sobre ela mesma. Seu discurso ainda sinaliza para uma dependência, tanto de outras pessoas, que precisam estar "sempre consolando", como da própria medicação, que neste caso assume o papel de contentora das crises. O consolo das pessoas e a medicação são fatores que se equiparam em importância, no discurso de Silene. É interessante atentar também para a sua lamentação pelo fato de ser bipolar, e pela distinção que faz entre saúde e doença, remontando à antiga discussão entre normal e patológico. Isto demonstra a força que o discurso médico ainda possui entre os usuários, mesmo com os serviços institucionais inovadores, constituídos por novas práticas, em pleno desenvolvimento da Reforma Psiquiátrica. Sobre isso, Pacheco (2011) pontua que vivemos um período de transição de modelos de atenção à saúde mental, no qual busca-se superar o modelo manicomial e estabelecer um modelo de reabilitação social. Uma vez que, apesar das transformações que já aconteceram na saúde mental, o processo de efetivação da Reforma Psiquiátrica ainda está em andamento, pois o modelo manicomial ainda não foi totalmente superado e nem o modelo de reabilitação psicossocial totalmente assimilado, resultando em uma concepção de que ambos serviços (hospitalocêntrico e psicossocial) são necessários e ainda assistem, simultaneamente, a população (Sousa, Maciel, Medeiros, \& Vieira, 2016).

Assim como na fala de Silene, nos discursos dos demais entrevistados os termos historicamente produzidos se fizeram presentes com muita ênfase. Foi comum encontrar várias definições de doença, traduzidas por expressões como "doente dos nervos", "especial", "diferente", "doente da cabeça", "fraco do juízo" e "distúrbio mental":

Entrevistador: Por que é que o senhor está aqui no CAPS? O que é que o senhor tem? Participante: 
[Silêncio]... Sou fraco.... sou [pausa] doente... Entrevistador: E como é essa doença? Participante: Da cabeça... Entrevistador: E como é essa doença da cabeça? Participante: É fraco [pausa] do juízo (Naldo, não lembra a idade nem há quanto tempo é usuário de serviço de saúde mental).

De modo geral, as falas dos participantes confirmaram o que foi dito por Minayo (1991, p. 233), de que "a doença é uma realidade construída e o doente é um personagem social". Com efeito, a persistência na utilização do termo doença, em detrimento de saúde mental, denota a dificuldade encontrada na reabilitação psicossocial destes sujeitos e o árduo processo de reconstrução de suas vidas. Ao reproduzirem os conceitos passados pela psiquiatria asilar, corroboram a estigmatização social, cultural, política e biológica da pessoa com transtorno mental (Jorge et al. 2008).

A apropriação de termos médicos também se fez notar no decorrer das entrevistas. A classificação de ansiedade e psicose aparece na fala da participante chamada Graça, para explicar a sua "incapacidade de cumprir horários" e a "agonia, um negócio ruim", que ela sente:

Entrevistador: Por que a senhora está aqui no CAPS? O que é que a senhora tem?

\section{Participante:}

Ansiedade e psicose... Isso ai atrapalhou o meu... o meu desenvolvimento no trabalho, eu não pude trabalhar, eu num [sic] sou capaz de... de... de cumprir horários, eu terminei o curso de pedagogia e não exerci por causa dessa ansiedade... Eu não posso cumprir horários, eu... me dá uma agonia, um negócio ruim, eu não sou capaz, a minha irmã depois de tudo, minha irmã um dia desses a minha irmã arranjou um emprego numa fábrica, cadê que eu cumpri horário? Num [sic] dá para ir, dá uma agonia uma vontade de sair correndo. Entrevistador: Hum... [pausa] E o que é ansiedade e psicose? Participante: Ansiedade é você querer fazer as coisas antes da hora, querer que aconteça logo [pausa] e a psicose é você tá [sic] com aquilo na cabeça, encuca as coisas na cabeça e tem que ser aquilo que você botou, vocêfica contra todos, mas tem que ser aquilo que você imagina que seja. (Graça, 52 anos, há 25 anos é usuária de serviço de saúde mental)

A todo instante, a entrevistada atesta a sua "incapacidade", repetindo para o entrevistador e para si mesma que "não é capaz". Com isso, reitera a ideia pela qual, durante o surgimento do capitalismo, se justificava a internação das pessoas com transtornos mentais em manicômios. Uma vez que não serviam aos interesses da sociedade, pois não eram "capazes" de produzir, essas pessoas eram enclausuradas. Como resumem Figueiró, Dimenstein e Oliveira (2009, p. 236), "Fora dos valores do trabalho da produção, a diferença que a loucura representa torna-se mais feia e ameaçadora".

Quanto à causa do transtorno mental, os participantes atribuíram tal fato à aspectos multicausais. Como pode-se observar em alguns relatos:

Participante:

Eu não sei se foi desde a morte da minha mãe, minha mãe quando morreu eu tinha 26 anos [pausa]... eu não sei se foi desde a morte da minha mãe que eu fiquei... as minhas irmãs disseram que eu fiquei fora de si [ㅎic] e que eu abraçava a minha mãe no caixão, isso ai eu me lembro, e que me deram um calmante, me doparam, ai de lá pra [icic] cá eu fiquei assim... Entrevistador: A senhora acha que ficou assim por causa da morte de sua mãe? Participante: Eu acho que foi, eu fiquei com essa enfermidade, eu fiquei com trauma, né? Eu acho que deve ter sido, minhas irmãs mesmo diz [ic] : 'Foi desde que mãe morreu que tu ficasse assim' (Graça, 52 anos, há 25 anos é usuária de serviço de saúde mental).

Participante:

Foi o trabalho, excesso de trabalho... Trabalhava na cana, ai fazia serão, ficava até dez e meia; onze horas ai de.... deu doença dos nervos e deu depressão... Foi excesso de trabalho. (Saulo, 52 anos, há 30 anos é usuário de serviço de saúde mental)

$\mathrm{Na}$ fala dos entrevistados, percebe-se que a causalidade do adoecimento mental está associada a diversos fatores; tal fato parece sinalizar as mudanças que já estão acontecendo no âmbito da saúde mental, desde o advento da Reforma Psiquiátrica. No novo contexto da saúde mental, o adoecimento psíquico é enxergado como multicausal, exigindo, portanto, de uma assistência multiprofissional (Costa-Rosa, 2012). Lançando mão de fatores variados para explicar o fenômeno do seu adoecimento, esses indivíduos parecem romper com a concepção monocausal e determinista, aproximando-se das ideias propostas pela Reforma Psiquiátrica. Nos discursos acima, é possível perceber que a perda de alguém próximo, e o excesso de trabalho, foram apontados como os desencadeadores do transtorno mental.

Apesar de dizer que não sabe qual foi a causa da sua "enfermidade", no desenvolvimento de seu discurso Graça utiliza os discursos de suas irmãs para confirmar que a morte de sua mãe lhe provocou um "trauma". Este trauma desencadeou comportamentos que fizeram com que a medicassem e a deixassem como "enferma". 
Saulo, por seu turno, aponta outro fator, típico da contemporaneidade e da agitação causada pela vida moderna. Apesar de trabalhar no meio rural, o excesso de trabalho e as horas estendidas no campo são responsáveis, segundo ele, por sua "doença dos nervos". O uso excessivo de bebidas também foi apontado como a causa do transtorno mental:

Entrevistador: a senhora acha que ficou assim por quê? Vendo essas coisas... escutando... Participante: Porque eu bebia muito; aí depois... [pausa] mas o psiquiatra lá do... do... Hospital Y, foi até Dr. G. que me atendeu, ele disse que isso não foi por causa da bebida, foi um distúrbio mental que... que eu peguei, um distúrbio mental (Fernanda, 53 anos, há 7 anos é usuária de serviço de saúde mental).

Fernanda acredita que o excesso de bebida é responsável por suas alucinações, mas em seguida dúvida dela mesma, quando relata que o médico atribui a sua sintomatologia a outra causa, ao fato dela ter "pegado um distúrbio mental". A utilização do verbo "peguei", no seu relato, remete à ideia de que os transtornos mentais são contagiosos, seguindo a lógica do discurso histórico estabelecido, e, portanto, os seus portadores devem ser mantidos distantes e isolados. Através do discurso de Fernanda, fica implicitamente colocado esse posicionamento, historicamente produzido e praticado, de que os usuários psiquiátricos devem ser mantidos distantes e reclusos.

\section{Sentidos produzidos sobre o hospital psiquiátrico e o tratamento oferecido}

Quando questionados, os entrevistados também rememoraram a primeira vez em que foram submetidos ao tratamento psiquiátrico. Diante das mudanças de comportamento dos usuários, a família (representada pelos pais, irmãos e cônjuge) ou a polícia foi responsável por levá-los ao hospital, no momento de sua crise:

\section{Participante:}

Ah, muito agressivo, né? A gente fica muito agressivo... A primeira vez... Infelizmente [grifo nosso] minha mãe teve que me internar no Hospital X, eu fiquei um mês e quinze dias lá dentro. (Silene, 29 anos, há 6 anos é usuário de serviço de saúde mental)

\section{Participante:}

Levaram pro Hospital Y, eu só vivia lá, passei mais de ano lá, me internava eu vinha pra casa, me internava eu vinha pra casa; passava três, quatro meses lá aí tava [sic] melhor vinha pra casa, aí dava crise de novo eu voltava pra lá, aí eu passei dois anos nessa situação... O meu marido, porque ele disse, ele [grifo nosso] que disse depois assim, que eu tava [sic] deitada na rua... toda nua...foram chamar ele aí... aí eu vim agitada, ai ele chamou um carro da viatura, aí me amarraram e levaram. (Fernanda, 53 anos, há 7 anos é usuária de serviço de saúde mental)

Os relatos de Silene e Fernanda mostram que a internação foi a maneira encontrada pelos seus familiares para lidar com o quadro de crise por elas apresentado. De acordo com Goffman (1988, p. 141), "esta forma de tratamento são os recursos geralmente usados pela sociedade para excluir, do seu convívio, os indivíduos que perfazem o tipo tradicionalmente definido como estigmático". Assim, quando perceberam certas mudanças de comportamento, como agressividade, agitação e rompimento da barreira da censura (como quebrar objetos, cantar ou andar nua na rua), os familiares identificaram, nestas condutas, a falta de razão das usuárias. Diante de tal situação, o hospital foi o único lugar a ser procurado por eles, por se constituir como o único local onde as pessoas com estes comportamentos eram aceitas.

Ao longo dos tempos, a sociedade lida com a loucura excluindo as pessoas com transtornos mentais do seu convívio; elas são banidas para espaços de reclusão, sendo isoladas e privadas do convívio social. O papel de recolher as pessoas com transtornos mentais foi por muito tempo atribuído unicamente aos hospitais psiquiátricos, os quais ofereciam tratamento para a suposta melhora da saúde dessas (Salles \& Barros, 2013).

No relato de Silene, a usuária enfatiza a palavra "infelizmente", ao falar que a sua mãe "teve" que interná-la no hospital. O uso do verbo "teve" refere-se à falta de alternativas, no momento de sua internação, uma vez que esta se deu antes da efetivação da reforma e da consequente modificação dos cuidados para com as pessoas com transtorno mental. Como lembra Melo (2012), até pouco tempo atrás a internação psiquiátrica constituía a única alternativa em saúde mental. Era administrada, quase que exclusivamente, pela iniciativa privada, não possuindo nenhum tipo de controle nem do Estado, nem da sociedade. Os longos períodos que as pessoas com transtornos mentais em crise ficavam internadas nos hospitais também são destacados nas falas das usuárias. Fernanda lembra, também, como eram constantes os seus retornos ao hospital e como, durante alguns anos, ficou dividida entre a sua casa e a internação.

Sobre os longos períodos de internação, Salles e Barros (2013) pontuam que na internação por longo prazo a vida do indivíduo para a ser a vida do hospital, o hospital se torna a casa da pessoa com transtorno 
mental, sua vida gira em torno das atividades do hospital; há um intenso rompimento com a vida em sociedade, é como se eles não existissem para o mundo fora daquela instituição. Tanto a internação prolongada, como as internações múltiplas, nas quais a pessoa com transtorno mental entra e sai dos hospitais psiquiátricos repetidas vezes, fazem com que os laços familiares e sociais se tornem cada vez mais frágeis, resultando no isolamento da pessoa com transtorno mental.

A falta de uma equipe técnica especializada para atender aos usuários, na ocasião de suas crises, fica visível no discurso de Fernanda. Antes de ser instaurado um tratamento mais humanizado a estes sujeitos, nesses momentos, a polícia era a única chamada para tentar contê-los e encaminhá-los aos hospitais. No entanto, o que se percebe ainda hoje, em pleno desenvolvimento da reforma, é a continuidade destas velhas práticas. A polícia é treinada para conter os indivíduos que apresentam risco à sociedade, não possuindo, portanto, nenhum treinamento para lidar com tais situações de transtornos mentais. Entretanto, continua sendo solicitada para estas chamadas, o que acarreta o uso indevido de violência, instaurado pela própria inabilidade e desconhecimento dos sintomas emergentes.

Para Brito, Bonfada e Guimarães (2015), nas entrelinhas de tais ações repressivas e marcadas pela violência estão as relações de poder que caracterizam a Psiquiatria Clássica e sua autoridade de tomar o corpo como objeto de suas práticas. Nesse sentido, tal forma de assistência vai de encontro ao ideário da Reforma Psiquiátrica e prejudicam a assistência as pessoas com transtornos mentais no contexto da crise. Tais autores ressaltam que não se pode seguir com a ideia de que toda pessoa em crise é potencialmente agressiva, isso é um reflexo do preconceito e da falta de preparo para as intervenções em urgências psiquiátricas

Com relação ao tratamento no hospital psiquiátrico, os usuários descreveram o que mais os incomodavam nestas instituições de internamento:

\section{Participante:}

Era mais pra...eu acho que eles tavam [sic] tentando afastar mais a gente do... do... dos outros, eu acho que lá era mais isso, pra trancar pra não prejudicar a ninguém, eu acho que lá era mais isso. Era horrivel [silêncio] acho que se tem um lugarzinho que eu não desejo pra ninguém era uma pessoa ficar internada naquele lugar, era horrivel, é horrivel, é horrivel, as mulheres tudo nua, você imagina, a maioria lá, tudo assim... outras lá deitada... o... olha... é uma coisa muito ruim é que tem que ficar amarrado também, né?
Entrevistador: Tem que ficar amarrado?

Participante:

Nossa [grifo nosso] Aquilo é... é... muito sei lá... eu acho muito [pausa] como é que eu posso dizer? [pausa] muito... violento, é uma violência muito grande, mesmo a gente, mesmo a gente estando meio que incontrolável, mas mesmo assim eu acho muito violento... as injeções também não são boas, nossa... dói muito aquele líquido lá [ininteligível] e o que também me incomoda é a maneira como era tratado lá [pausa] como um animal... eu acho que tem animal que é melhor tratado que o povo lá de dentro, viu? [risos] é... sei lá... era porque era muito... muito... muito sujo, sei lá... o pessoal... sei lá... eu tava [sic] num lugar lá trancada e eles jogavam com o pé a comida, botava o prato no chão e jogava, né? E ... não tinha cama... eram sujos os quartos, os quartos não, né? Eram uns comodozinhos bem pequeninhos que eles botavam uns colchão [sic]... colchão... umas almofadas verdes assim ... uns colchão [sic] horrivel, eu peguei uma peste de piolho tão grande [grifo nosso] que misericórdia... quando eu cheguei em casa era... horrivel. (Silene, 29 anos, há 6 anos é usuária de serviço de saúde mental)

Ao fazerem uso de suas memórias, os entrevistados constroem um sentido sobre o hospital, sobre o tratamento ofertado e sobre sua própria condição enquanto sujeitos humanos. A reclusão, a violência, a sujeira, a infestação por insetos, a contenção e os maus-tratos foram algumas das vivências relatadas.

A usuária Silene afirma que o objetivo do hospital era manter os internos afastados dos outros, que neste caso seriam os possuidores da razão. A segregação é percebida por ela, quando descreve as condições do hospital e enfatiza, através da repetição do termo, o quanto era "horrível" aquele "lugarzinho". Através do uso do diminutivo ("lugarzinho"), atribui um caráter ainda mais pejorativo à instituição. A violência e os maus-tratos colocavam as pessoas na posição de animais ("como um animal"), trancados em uns "comodozinhos", com a comida sendo colocada no chão, em um lugar sujo, com as pessoas nuas e com piolhos.

O discurso de Silene corrobora os relatos encontrados na literatura especializada sobre a assistência em saúde mental nos hospitais psiquiátricos (Barbosa, Souza, \& Dimenstein, 2009; Kinker, 2017; Szasz, 1978) e evidencia a impotência do modelo manicomial na assistência as pessoas com transtornos mentais. Em sua fala, é possível observar que a segregação se faz presente na vida destas pessoas e que o fato de se encontrarem em crise no momento da internação não diminuiu a sua percepção sobre as 
condições subumanas a que foram expostas. Cabe ressaltar, porém, que o discurso foi marcado pelas condições vividas naquele momento do internamento, podendo o sentido atribuído aos hospitais ter sido ressignificado com a passagem do tempo, podendo, portanto, assumir uma forma diferente nos dias atuais.

\section{Sentidos produzidos sobre a relação dos usuários com a comunidade}

Os participantes da pesquisa foram também entrevistados com o intuito de detectar os impactos produzidos pela Reforma Psiquiátrica no tocante à relação com a comunidade na qual estão inseridos. Os entrevistados foram questionados sobre a percepção que têm desta relação, dos sentimentos que experimentam sobre esta questão e se sentem diferença no tratamento que os outros lhes dirigem, ao saber que eles são usuários de serviço de saúde mental:

\section{Participante:}

Eu não digo porque eu sei que existe rejeição, as pessoas começam a olhar de um jeito diferente pra gente, tanto que nem na igreja eu num [sic] digo que venho pro CAPS, digo não... porque se eu digo na igreja que venho pro CAPS a alguém, as pessoas vão dizer: "irmã a irmã tá com pouca fé" e num [sic] sei o que lá "pede a Deus que ele te liberta", mas só que não é por aí, do jeito que a pessoa tem uma dor de cabeça... uma gripe... um câncer... do mesmo jeito é essa enfermidade, essa enfermidade a gente tem que separar a enfermidade mental da parte espiritual; eu sou uma serva de Deus, eu não deixo de ser uma serva de Deus porque eu tô [ic] no CAPS não... mas só que na igreja eu não posso falar que eu tô [sic] no CAPS, porque se eu falar vão me discriminar, vão me dizer "oxente, que fé é essa que a irmã tem? A irmã precisar ir para o CAPS... Jesus é o nosso libertador, Jesus é isso, é isso, é aquilo" eu olhe, eu venho para cá e num [ic] digo a ninguém, só quem sabe é a minha família, nem todos da família sabe. (Graça, 52 anos, há 25 anos é usuária de serviço de saúde mental)

\section{Participante:}

Sinto... Ninguém me dá emprego [pausa]... ninguém dá emprego a quem sofre de nervo não [silêncio]... A gente somos [sic] humilhado, a família... muitos da nossa familia têm vergonha da gente [silêncio]... pelos outros [pausa] minha família mesmo, a minha sobrinha mesmo só me dá a benção dentro de casa, na rua ela num [sic] me dá a benção não. (Darlene, 50 anos, há 43 anos é usuária de serviço de saúde mental)

Mesmo com o advento da Reforma Psiquiátrica, com os diferentes tratamentos e serviços hoje oferecidos, além do novo lugar de cidadão, assegurado legalmente pelo Estado, a discriminação ainda é sentida pelos usuários em saúde mental, conforme aponta a literatura (Barbosa, 2010; Mfoafo-M'Carthy \& Huls, 2014; Ross \& Goldner, 2009). Apesar dos avanços advindos com a nova política de assistência à saúde mental, a sociedade ainda percebe a pessoa acometida por um transtorno mental como alguém de pouco valor e tem fortemente arraigada a crença de que estas pessoas são incapazes de construir o seu cotidiano fora das instituições. Isso contribui para uma visão preconceituosa e dificulta a reinserção social das pessoas que sofrem com algum transtorno mental, fazendo com que esses indivíduos vivenciem uma realidade de preconceito e exclusão (Jiwon \& Chasteen, 2016).

Ratificando o mal-estar sentido por estes usuários, Graça classifica o que sente valendo-se do termo "rejeição". Exemplificando o que sente, realiza uma analogia entre algumas enfermidades, como "dor de cabeça... uma gripe... um câncer..." e a "enfermidade mental". Fazendo isto, ela acredita se isentar da culpa que lhe iriam atribuir por ter "essa enfermidade" e demonstra a vulnerabilidade a que todos estão submetidos. Outro ponto a ser destacado é o medo que a usuária sente de ser rejeitada por duas instituições sociais que, segundo a cultura ocidental, deveriam dar conforto e acolhida: a família e a igreja. Sendo uma "serva de Deus", Graça acredita que, além de a olharem "de um jeito diferente", seus "irmãos" (os demais membros da igreja) iriam por em dúvida a sua fé e isto faz com que ela mantenha segredo sobre a sua condição de usuária de um CAPS.

Corroborando esta ideia de rejeição, Darlene utiliza o termo "vergonha", para descrever o que os familiares sentem quando algum dos seus membros apresenta transtornos mentais. A humilhação é sentida por estes usuários, que preferem se manter ocultos. Mesmo para os que tentam restabelecer a sua cidadania, através de atos simples como o trabalho, esbarram no preconceito, o que dificulta ainda mais a sua inserção na sociedade, que ainda os vê como incapazes. "A exclusão não se restringe apenas a desintegração do mercado de trabalho, mas refere-se também a uma ruptura dos laços sociais e familiares" (Leão \& Barros, 2008, p. 96).

Ao longo dos tempos, a sociedade enxerga a pessoa com transtorno mental de forma negativa, considera-o como sem razão/sem juízo, agressivo e, portanto, perigoso e incapaz de viver em sociedade, devendo ser excluído da família e do meio social e mantido em instituições psiquiátricas (Haqanee, Lou, \& Lalonde, 2014).

Paes, Maftum e Mantovani (2010) apontam que a manutenção dessas concepções equivocadas sobre a 
pessoa acometida por transtorno mental, influenciadas pela história da psiquiatria e pautadas nos moldes manicomialistas, influenciam negativamente a efetivação Reforma Psiquiátrica, na medida em que dificultam o processo de reabilitação psicossocial.

A reestruturação do cuidado em saúde mental implica na convivência e interação social com as pessoas com transtornos mentais, ampliando as oportunidades destas para as relações sociais, e a manutenção de ideias equivocadas acerca desses indivíduos favorece a resistência da comunidade ao processo de reintegração de usuários da saúde mental (Ribeiro, Avellar, \& Tristão, 2017).

Para que as mudanças no campo da saúde mental de fato se efetivem é necessário a participação de toda a sociedade e empenho desta em acolher no seu cotidiano as pessoas com transtornos mentais, cabe ressaltar ainda a importância de se disseminar uma visão realista e humana acerca da doença mental (Silva, 2014).

Através da análise dos sentidos produzidos pelos participantes foi possível observar que a proposta de uma psiquiatria reformada, com novos dispositivos de saúde mental e uma legislação que assegurasse novos direitos aos usuários, não foi ainda capaz de produzir transformações nas as relações de exclusão e rejeição sofridas por estas pessoas. Ainda prevalece um olhar voltado para a doença e não para o sujeito que apresenta suas especificidades e o hospital psiquiátrico ainda é sentido como um lugar de isolamento e maus-tratos.

\section{Considerações finais}

Por meio das falas dos participantes dessa pesquisa pôde-se observar a presença de uma grande variedade de nomenclaturas para designar o transtorno mental. Foi comum encontrar, nos discursos dos usuários, termos historicamente produzidos, ligados à definição de doença e carregados de preconceito. Já os sentidos produzidos sobre a causa desses transtornos mostraram-se variados, mas sempre ligados a fatores externos: a morte de alguém, a desilusão amorosa, o excesso de trabalho ou o uso de bebidas. O que representa um avanço e indica uma compreensão do adoecimento mental enquanto algo multicausal, como propõe a Reforma Psiquiátrica.

Os sentidos produzidos pelos usuários sobre o tratamento oferecido nos hospitais psiquiátricos denunciam um lugar de maus-tratos e exclusão; nesses hospitais, eles eram submetidos a uma precária condição de sobrevivência, expostos à sujeira, à violência, uma equipe despreparada e isolamento social. Quanto a inclusão social, observou-se nas falas dos participantes que eles são vistos de forma negativa pela sociedade e são alvos de preconceito.

O advento da reforma e os novos dispositivos utilizados pelos usuários, não foram ainda capazes de provocar mudanças significativas na sua relação com a sociedade, a qual, segundo eles, ainda os rejeita e discrimina. Persistem ainda certos estigmas sobre os portadores de transtornos mentais, como, por exemplo, de que envergonham as famílias e são improdutivos, o que dificulta a socialização destes sujeitos. Assim, mesmo quando tentam desempenhar atos simples, como estabelecer um vínculo empregatício, por exemplo, essas pessoas têm muitas vezes a sua autonomia ameaçada e não conseguem exercer a sua cidadania.

A detecção da persistência destes fatos mostra que é de fundamental importância que as práticas de exclusão sejam abolidas e que sejam difundidos, entre a comunidade e entre os próprios usuários, os seus direitos enquanto cidadãos. Assim se possibilitaria alcançar uma ressignificação dos mitos e preconceitos cristalizados ao longo da história. Além da derrubada dos muros do hospital é fundamental o desmantelamento da muralha dos preconceitos, para que seja garantida a liberdade destes usuários, que ainda se veem acorrentados ao estigma da doença.

Uma vez que este estudo se limitou à análise das produções discursivas dos usuários, não contemplando outros atores envolvidos no processo da Reforma Psiquiátrica, espera-se que os dados encontrados possam instigar o desenvolvimento de pesquisas futuras, que envolvam outros grupos sociais, tais como profissionais, familiares, entre outros.

$O$ fato de se tratar de um estudo de cunho qualitativo pode refrear o alcance da generalização dos dados. Outra limitação encontrada está relacionada às variáveis típicas de um CAPS, como a dinâmica das atividades desenvolvidas no serviço, que muitas vezes interferiam no andamento das entrevistas e as particularidades apresentadas por cada usuário. Os espaços utilizados para a realização das entrevistas (o próprio CAPS) também podem ter influenciado, de alguma forma, os discursos dos usuários.

Porém, as limitações apresentadas não inviabilizam, nem retiram a importância dos achados dessa pesquisa, os quais permitem demonstrar, a partir da ótica dos usuários do CAPS, como a Reforma acontece no dia-a-dia na vida desses sujeitos. As falas dos participantes, embasadas em suas vivências, deixam explícito o quanto ainda precisamos avançar, o quanto mais precisamos fazer para que de fato a 
Reforma Psiquiátrica se efetive. Existem avanços, isso é inegável, muita coisa melhorou, mas ainda se tem um caminho longo a percorrer.

\section{Referências}

Sousa, P. F., Maciel, S. C., Medeiros, K. T., \& Vieira, G. L. S. (2016). Atitudes e Representações em Saúde Mental: um Estudo com Universitários. Psico-USF, 21(3), 527-538

Amarante, P. \& Nunes, M. O. (2018). A reforma psiquiátrica no SUS e a luta por uma sociedade sem manicômios. Ciência \& Saúde Coletiva, 23(6), 2067-2074.

Barbosa, T. R. S. (2010). Estigma face à doença mental por parte de futuros Profissionais de saúde mental. Dissertação de Mestrado, Faculdade de Psicologia e de Ciências da Educação da Universidade do Porto, Portugal.

Barbosa, V., Souza, P. K., \& Dimenstein, M. (2009). Trabalhadores de saúde mental frente ao fechamento de um hospital pisquiatrico. In M. Dimenstein (Org.), Produção do conhecimento, agenciamento e implicação no fazer pesquisa em Psicologia (pp. 315-334). Natal: Editora da UFRN.

Brito, A. A. C., Bonfada, D., \& Guimarães, J. (2015). Onde a reforma ainda não chegou: Ecos da assistência às urgências Psiquiátricas. Physis: Revista de Saúde Coletiva, 25(4), 1293-13.

Costa-Rosa, A. (2012). A instituição de saúde mental como dispositivo social de produção de subjetividade. Estudos de Psicologia, 29(1), 115-126.

Feitosa, A., Horvat, C. C., Diegues, D., Manuchakian, F., Ratcov, I., Muniz, J. A., Perez, L. B., Finotti, M., \& Domingues, A. R. (2010). Estudo das experiências da reforma psiquiátrica Concepções de sujeito, comunidade e práticas terapêuticas. Mnemosine, 6(1), 111-133.

Figueiró, R., Dimenstein, M., \& Oliveira, I. F. (2009). Reflexões sobre o manicômio: experiência de um psicólogo no contexto da reforma psiquiátrica. In M. Dimenstein (Org.), Produção do conhecimento, agenciamento e implicação no fazer pesquisa em Psicologia (pp. 233-247). Natal: Editora da UFRN.

Firmo, A. A. M. \& Jorge, M. S. B. (2015). Experiências dos cuidadores de pessoas com adoecimento psíquico em face à reforma psiquiátrica: produção do cuidado, autonomia, empoderamento e resolubilidade. Saúde e Sociedade, 24(1), 217-231.

Gill, R. (2002). Análise de discurso. In M. W. Bauer \& G. Gaskell (Orgs.), Pesquisa qualitativa com texto, imagem e som: um manual prático (pp. 244-270). Petrópolis, RJ: Vozes.

Goffman, E. (1988). Estigma: notas sobre a manipulação da identidade deteriorada. Rio de Janeiro: LTC.

Haqanee, Z., Lou, E., \& Lalonde, R. N. (2014). Natural kind and entitative beliefs in relation to prejudice toward mental disorders. Journal of Applied Social Psychology, 44, 145153.

Iñiguez, L. (2004). Os fundamentos da análise do discurso. In Manual de Análise do Discurso em Ciências Sociais (pp. 50103). Petrópolis, RJ: Vozes.

Jiwon, J. \& Chasteen, A. L. (2016). Does imagery reduce stigma against depression? Testing the efficacy of imagined contact and perspective taking. Journal of Applied Social Psychology, 46(5), 259-275.
Jorge, M. S. B., Ramirez, A. R. A., Lopes, C. H. A. F., Queiroz, M. V. O., \& Bastos, V. B. (2008). Representações sociais das famílias e dos usuários sobre participação de pessoas com transtorno mental. Revista da Escola de Enfermagem da USP, 42(1), 135-142.

Kinker, F. S. (2017). Um hospício em crise: imagens de uma experiência de desinstitucionalização. Interface Comunicação, Saúde, Educação, 21(60), 189-198.

Leão, A. \& Barros, S. (2008). As representações sociais dos profissionais de saúde mental acerca do modelo de atenção e as possibilidades de inclusão social. Saúde $e$ Sociedade, 17(1), 95-106.

Lei n. 10.216, de 06 de abril de 2001. (2001). Dispõe sobre a proteção e os direitos das pessoas portadoras de transtornos mentais e redireciona o modelo assistencial em saúde mental. Brasília, DF: Ministério da Saúde.

Lima, L.T. \& Surjus, S. (2007). Narrativas Políticas: o olhar dos usuários sobre os caps (Centros de Atenção Psicossocial). Dissertação de Mestrado, Programa de Pós-graduação em Saúde Coletiva, Universidade Estadual de Campinas, São Paulo, SP.

Melo, A. M. C. (2012). Apontamentos sobre a reforma psiquiátrica no Brasil. Cadernos Brasileiros de Saúde Mental, 4(9), 84-95.

Mfoafo-M'Carthy, M. \& Huls, S. (2014). Human rights violations and mental illness: implications for engagement and adherence. SAGE Open, 4(1), 1-18.

Mielke, F. B., Kantorski, L. P., Jardim, V. M. R., Olschowsky, A., \& Machado, M. S. (2009). O cuidado em saúde mental no CAPS no entendimento dos profissionais. Ciência \& Saúde Coletiva, 14(1), 159-164.

Minayo, M. C. S. (1991). Abordagem antropológica para avaliação de políticas sociais. Revista de Saúde Pública, 25(3), 233-238.

Minayo, M. C. S. (1995). Pesquisa Social: teoria, método e criatividade. Petrópolis, RJ: Vozes.

Pacheco, J. G. (2011). Representações sociais da loucura e práticas sociais: o desafio cotidiano da desinstitucionalização. Tese de Doutorado, Programa de Pós-graduação em Psicologia Social, do Trabalho e das Organizações, Universidade de Brasília, Brasília, DF.

Paes, M. R., Maftum, M. A., \& Mantovani, M. F. (2010). Cuidado de enfermagem ao paciente com comorbidade clínico-psiquiátrica em um pronto atendimento hospitalar. Revista Gaúcha de Enfermagem, 31(2), 277-284.

Potter, J. \& Wetherell, M. (1987). Discourse and Social Psychology: beyond attitudes and behavior. London: Sage.

Ribeiro, P. M., Avellar, L. Z., \& Tristão, K. G. (2017). Convivência social com moradores de residências terapêuticas. Psicologia \& Sociedade, 29, 23-35.

Rodrigues, A. C. \& Yasui, S. (2016). Oficinas de geração de trabalho e renda na atenção psicossocial: reflexões sobre um equipamento e suas produções de cuidado. Cadernos Brasileiros de Saúde Mental, 8(20), 01-21.

Ross, C. A. \& Goldner, E. M. (2009). Stigma, negative attitudes and discrimination towards mental illness within the nursing profession: A review of the literature. Journal of Psychiatric and Mental Health Nursing, 16, 558-567.

Salles, M. M., \& Barros, S. (2013). Representações sociais de usuários de um Centro de Atenção Psicossocial e pessoas de sua rede sobre doença mental e inclusão social. Saúde e Sociedade, 22(4), 1059-1071. 
Shimoguiri, A. F. D. T. \& Costa-Rosa, A. (2017). Do tratamento moral à atenção psicossocial: a terapia ocupacional a partir da reforma psiquiátrica brasileira. Interface - Comunicação, Saúde, Educação, 21(63), 845-856.

Silva, G. L. S. (2014). A doença mental e a reforma psiquiátrica representadas por profissionais de saúde. Dissertação de Mestrado, Programa de Pós-graduação em Psicologia Social, Universidade Federal da Paraíba, João Pessoa.

Szasz, T. S. (1987). A fabricação da loucura: um estudo comparativo entre a inquisição e o movimento de saúde mental. Rio de Janeiro: Zahar.

Submissão em: 06/11/2017

Aceite em: 14/10/2018

Giselli Lucy Souza Vieira é Mestre em Psicologia Social/ UFPB. Atualmente, é professora da Faculdade de Ciências Médicas da Paraíba e doutoranda em Psicologia Social pela Universidade Federal da Paraíba https://orcid.org/0000-0002-0604-6398 Endereço para correspondência: UFPB. Campus I. Cidade Universitária, João Pessoa/PB. 58033-455. E-mail: giselli_psi@hotmail.com
Livia Sales Cirilo é Doutora em Psicologia Social/ UFPB. Atualmente, é professora da Universidade Estadual da Paraíba.

https://orcid.org/0000-0003-2651-1928

E-mail: liviasalesc@gmail.com

Patrícia Sousa é Mestre em Psicologia Social/UFPB. Atualmente, é doutoranda em Psicologia Social pela Universidade Federal da Paraíba. https://orcid.org/0000-0003-1885-2626 E-mail: patriciasousa20@yahoo.com.br

Silvana Carneiro Maciel é Silvana Carneiro Maciel é Pós-doutora em Psicologia Social pelo ISC-Portugal. Atualmente, é professora da graduação em Psicologia e pós-graduação em Psicologia Social da Universidade

Federal da Paraíba.

https://orcid.org/0000-0003-1489-1126.

E-mail: silcamaciel@gmail.com 